\title{
Exploration on the Ways of Thinking for Government by Law in the Governance of the Grassroots Society
}

\author{
Xuzhi Fan \\ Department of Humanities and Social Science, Hubei Polytechnic University, Huangshi, Hubei, China \\ Email:1302928893@qq.com
}

\begin{abstract}
Social governance of the grassroots is the foundation for maintaining social stability and building a harmonious society. The obvious problems of weakened power, abnormal petitioning, hidden danger of social security, weakness of virtual social control, and vacancy in management of the special group in the vast grassroots area did exist. Faced with the problems, the rapid development of urbanization and the relative lack of public service, the public's strengthened consciousness of rights safeguarding and not sound interests safeguard mechanism, heavy tasks on social governance of the grassroots and not enough resources, and the imbalance between the public's improved expectation and the ability of the cadres in grass-root level, the level of grass-roots social governance needs to be improved by employing the "five-in-one" thinking mode of governance by law.
\end{abstract}

Keywords. Grass-root, social governance, thinking mode of governance by law, mass disturbance.

\section{Introduction}

Although "social management" and "social governance" are not quite different from each other literally, they are different in the aspects of behavioral agents, operation modes and purposes of implementation, etc. The transformation from top-down "management" to the combination of top-down "governance" employed by the government and top-down "governance" of the society is the great reform in idea of governing a country [1]. In such profound reform, ability of cadres at the grass-roots level shall be improved so as to cultivate their work of "deepening reform, promoting development, solving contradiction, and maintaining stability" by employing the thinking mode of governance by law and the method of governance by law [2].

\section{The main problems exist in social governance of grassroots level}

Firstly, it is about the existence of weakened power in grassroots level. The grass-roots regime is situated in the bottom of the pyramid-structured state regime. Determined by its historical uniqueness, its dependence on the grass-roots government in managing everything well cannot be fulfilled. Power of the grassroots social organizations is often weak and dispersed, and power of the rural community is more limited, which results in the fact that a lot of social affairs in the 
countryside are unable to be dealt with. Thus, there are many blank points and weak points. Election would be affected by clan power in some area.

Secondly, the tendency of abnormal petition remains high in level. Petition is the public's solution to the problems relating to their own vital interests, and dealing with the petitions well is also the responsibility of the grass-roots party organizations. In recent years, proportion of collective petition for grass-roots society, repeated petition, petition bypassing the immediate leadership and abnormal petition is relatively high, and such cases would lead to the abnormal petitions of trouble-making petition, direct petition to the provincial capital and Beijing and even mass incidents if they are not fairly dealt with. As in 2015, collective petition in city A is about 318 batches and 6816 person-time, which rose $8.9 \%$ and $38.2 \%$ respectively on year-on-year basis, and they accounted for $19.4 \%$ and $76.3 \%$ respectively of the total petition that year; the number of repeated petition is 646 batches and 4247 person-time, which accounted for $39.3 \%$ and $47.6 \%$ respectively of the total petition that year [3].

Thirdly, there are large quantities of hidden danger in the problems of social security, while social disputes are complex and diverse. Along with the social openness and further enhanced mobility, many new situations exist in security management and the total volume of social criminals in the grassroots in our country in recent years shows a rising tendency. Burglary, purse-cutting in public places, and loot etc. seriously influence the public's personal property security; the illegal criminal activities, such as problems on rental houses which is linked to security in life, occur frequently; economic crimes involving the mass, such as illegal fund raising, financial crime, telecom fraud, financial fraud, and pyramid schemes etc., shows a tendency of extension.

Fourthly, the control over virtual society is still weak. The development of "Internet + " is both a blessing and a curse at the same time. Along with the gradually strengthened management and control system of urban network, the crime, committed by employing "high-tech + network", is extending to the grassroots, especially the vast rural areas. Crime presents a dynamic, organized, and intelligent trend [4, 5]. For instance, illegal and criminal activities, such as fraud, gambling and pornography etc. committed through network, even form the elusive criminal organizations that are based on the network platform and crime of the new form and new means is being repeated brought out in grassroots society.

Fifthly, there is much vacancy in the control over special groups. In promoting economic development, the middle-aged, which accounts for more than $50 \%$ of the population in rural area, work out as migrant workers and the left-behind children reaches more than $30 \%$ of the total population. Because they lack parents' affection, care, education and guidance, plus the induction of some adverse factors on the minor in the society, the issue of "problem child" raises severe challenges to grassroots social governance.

\section{Reason-analysis on the causes to the of the dilemma of social governance in the grassroots}

1.The contradiction between the rapid development of urbanization and relative shortage of public services

The quickened progress of urbanization provides economic and social development with vitality. At the same time, the rapidly expanded urban population leads to intensive allocation of resources. Moreover, the obvious lag of public service and the lack of public facilities results in increased conflicts in all sorts of interest. Thus, contradiction would easily happen in large number in reconstruction of old city, land requisition and demolishment, enterprise restructuring, medical disputes, labor disputes, job placement, law and litigation involved, and food and drug safety etc.

2.Contradiction between enhanced right-protection awareness of the public and not sound safeguard mechanism on interests

Channels for the public's interest appeal are not smooth, and the mechanism with smooth communication for contradiction resolving covering the mechanism of troubleshoots and early warning is not sound. In addition, some departments pay insufficient attention to the masses and they'd shuffle. Moreover, problem solving stays in form, and someone would even show the mood of resistance. Part of the grassroots cadres are still used to administrative commands or take compulsory measures. According to survey, $38 \%$ of the cadres in city A think that the major obstacles to grassroots work is that the method is not suitable, and it is believed that $46 \%$ of the cadres lack service consciousness and service 
ability. What's more, some people would have instinct panic in the work of grassroots land requisition and demolishment, as well as petition and safeguard stability, and the masses' satisfaction in the village and town over the cadres is less than $70 \%$.

3.The contradiction between heavy tasks and not enough resources in grassroots social governance

Grassroots communities (villages) undertake the heavy task of social governance, but they have not yet reached the goal of "power goes along with responsibility and the passing of costs system accompanies duty", which leads to the phenomenon of "3 Nos" in part of grassroots departments - "no measures in their work, no power owned by the coordinating departments, and no resources to serve the public". Especially in rural areas, the public's enthusiasm in participating villagers' autonomy, social undertakings and social governance would be reduced. Instead, about $70 \%$ or $80 \%$ of the villagers thought that they can only gain the sense of belonging by participating the clan-related activities, such as being written on the pedigree of their clan, building ancestral temple, and amending their family tree. Some villagers are attracted by superstition power in clan and they'd choose the latter as to leadership of the party organizations at the grass-roots level and clan power. Cadres and the masses at the grass-roots level are deeply affected by the ideas of power over legislation, love over legislation, representing legislation with customs, being ashamed of litigation and the inability of legislation to the majority.

4.The contradiction between the public's expectation and ability of grassroots cadres

The grassroots masses not only focus on social development dynamic, but also hope to have a platform where they can make comments and express their viewpoints. Some cadres at the grass-roots level have no broad vision and no liberated thoughts, and they' $\mathrm{d}$ work by depending on their own feelings, experience and authority work. Thus, they'd do less work on demonstration, guidance service, and more work on certain relationship. Moreover, they'd depend on law less and lack the concept of legal thinking. Considering the questionnaire survey in rural area and grassroots that is aimed at the party branch secretary of the villages, $53 \%$ of the respondents in city A think that the most prominent problem lies in the not strong consciousness of dedication; $27.7 \%$ of the respondents think that their motivation of being in office is seeking for gains of themselves and their clans; $29.7 \%$ of the respondents believe that they want to be spokesperson of the interests owned by the small collectives.

\section{Exploration on the ways of thinking for government by law in the governance of the grass-root society}

Based on the above-mentioned problems and difficulties, it is discussed from the macroscopic angle of legislative thinking mode that whether most party members and cadres at the grass-roots level should treat legislation and the way to obey the law as an important value orientation in planning work, judging the right and the wrong and dealing with problems so as to deal with problems according to the provisions and procedure of law. Legal thinking has certain directivity, and it has the characteristics of openness. Legal thinking should include the five basic connotations of systematicness, fairness, constructiveness, contractuality and proportionality, and it plays a important role of guidance, support and security in promoting the ability of social governance in grassroots.

1. Realize the certainty of the grassroots social governance by employing regular thinking mode. To build the grassroots society with the rule of law where impersonalization prevails, people at the grassroots level shall obey the same rules. As people at the grassroots level has strengthened consciousness of rights protection and relatively weak consciousness of rules, grassroots cadres shall think about the universality of problems that they are faced with. If relevant work are done at the expense of the authority of law, or problems are dealt with for a short time by attaching importance to specialty, and the present and individual interest is satisfied by sacrificing the excessively high social cost, then it will not only fails the grassroots people's expectations, but also lead to new social problems. If things continue this way, it will seriously interfere with the process of our modernization.

2. Realize the harmony of the grassroots social governance by employing fair thinking mode.

Fair thinking refers to the thinking mode which is employed by all the social members who maintain their own interest and harms not the interest of others, our country and the collective in the legal framework. Public power refers to the truth 
that "law is infeasible if it is unauthorized" and civic power refers to the fact that "law is feasible if it is not forbidden". Practice shows that the grassroots attaches great importance to the equity of resources and public service. If cadres at the grassroots level abuse their power to damage fairness and justice, it will greatly reduce the grassroots' trust on organizations of public power. To maintain the dignity of the rule of law, the bad thoughts of attaching importance to power and management while thinking lightly of rights and service should be full eradicated so as to realize the justice of procedure and entity.

3. Achieve the sustainability of grassroots social governance by using constructive thinking.

Constructive thinking is generally a kind of thinking mode that starts from the general problems so as to find the common factors, and then it is ascended and solidified into the system that can be implemented and generally obeyed. Thus, the public can make judgment that can be expected by their own behavior. The grassroots cadres shall set up orientation of the public will, respect the public's pioneering spirit, find problems from the public opinion, take analysis and settlement of the public will into consideration, and nurture people's belief toward the rule of law.

4. Achieve the honesty of grass social governance by using contractual thinking. Contractual thinking refers to the communication in life and production with contract (system) as the link and honesty as the basis. Chinese society in the past, especially the grass-roots society, is relatively closed, and relationship among people is called the "society of acquaintance". Moreover, the main body of social interaction is also the network of acquaintance. The current China is going through the profound transformation period from the "society of acquaintance" to the "society of strangers" [4]. The times of contract's gradual growth and formation is also the transformation period from "identity" to "contract". Cadres at the grass-roots level shall deepen their understanding on the trend of social development and grasp the direction and trend of legal construction scientifically so as to build up trust and undergo communication with contract and system as the link, and build up the harmony of grassroots society by the establishment of contract, following the contract, and safeguarding the contract.

5. Achieve the uniformity of grass social governance by using balanced thinking. Things in the world are complicated and they'd relate to each other. The legal issues shown by the contradictions that are interweaved and interplayed contain more complicated economic and social problems. It is required that the issues should be viewed from two, three and even more angles. If it is analyzed and dealt with from the angle of law and technique, it is difficult to be settled and it may also lead to chain reaction. If it is considered more thoroughly and the scheme is designed more carefully, the negative impact can be minimized and win-win effect between the pursuit of personal value and collective value even multi-win can be attained. Thus, the unification between development and harmony, rights protection and stability safeguarding, and formal justice and substantive justice can be achieved. In the process of concrete practice, law should be abided and subjective initiative should be exerted so as to reasonably employ the philosophy of law enforcement. That is, comprehensive factors should be taken into consideration in evaluating the advantages and disadvantages, right or wrong, and the pros and cons of things.

\section{Acknowledgements}

1.Connotative Development and Research for Public Cultural Service of Grassroots Community supported by open fund of public culture for key study base of the humanities and social science in Hubei province in 2015 Item No.: 2015 kyb06

2. Analysis on the Response and Disposal of Sudden Mass Disturbance supported by Scientific Research Projects of Hubei Polytechnic University in 2009

\section{References}

1. Wei Wanbin, The New Success in the Concept of Governing a Country. Journal of History of the Party in Beijing. Forum Vol.1(2014),p.23

2. Walking along the Path of Socialism with Chinese Characteristics and Striving to Build A Well-off Society in an All-round Way-Report on the 18th National Party Congress of the Communist Party of China. 
3. Information on http://www.xj.xinhuanet.com

4. Sun Xixin, Zhang Zhaoli, Don't Make Clan "Obstacle" in Maintaining Harmonious Stability in Rural Area. Journal of Life of Party Branch (Shandong). Forum Vol.7 (2010),p.29.

5. Zhang Yan, Law and Morality of Strangers' Society. Journal of China Book Review. Forum Vol.3 (2012),p.45. 